\title{
Synthesis, Structure Investigation and Dyeing Assessment of Novel Bisazo Disperse Dyes Derived from UV Absorbing Material
}

\author{
Hitendra M. Patel \\ Department of Chemistry, V. P. \& R. P. T. P. Science College, Affiliated to Sardar Patel University, Vallabh \\ Vidyanagar-388120, Gujarat, India,
}

\begin{abstract}
Novel bisazo-disperse dyes were prepared by the coupling of diazotized solutions of various aromatic diamines with 2,4-dihydroxybenzophenone. The resultant bisazo disperse dyes were characterized by elemental analysis, IR and ${ }^{I} H$ NMR spectral studies. The UV Visible absorption spectral data were investigated in dimethylformamide. and are discussed in terms of structural property relationship. Their dyeing assessment of bisazo disperse dyes has been made on polyester fabrics. The results show that a better hue was obtained on polyester fabrics and have mild to moderate fastness properties.
\end{abstract}

Keywords: Bisazo disperse dyes, light fastness, polyester fabrics, UV-absorber, washing fastness.

\section{INTRODUCTION}

In the history of disperse dyes, the phenolic and several heterocyclic compounds can play the important role for the most of commercial dyes [1-6]. Most of the bisazo disperse dyes [7] are marketed in the form of azo disperse, azo-vat, azo-acid dyes etc. All these have part of phenols naphthols and heterocyclic compounds having hydroxyl group as auxochrome group. One of the hydroxy compound i.e. 2, 4-dihydroxybenzophenone having hydroxy (as auxochrome) groups and a keto (chromophore) group. This compound has wide applications as an excellent UV absorber [8,9] which prevents the photo degradability of most of vinyl polymers [10]. The area in which the bisazo disperse dye formation based on this compound has not been developed except of few patents $[11,12]$. The formation of dyes based on this heterocyclic compounds may yield with good hue properties. Hence, it was thought interesting to explore the field of bisazo disperse dyes based on derivatives of benzophenone. The present communication comprises the studies on novel bisazo disperse dyes based on 2, 4dihydroxybenzophenone.

\subsection{Materials and methods}

\section{EXPERIMENTAL}

All the chemicals used were of commercial grade and were further purified by crystallization. Melting points were determined by open capillary method and are uncorrected. The visible absorption spectra were measured on a Carl Zeiss UV/VIS Specord spectrometer, elemental analysis were carried out on Perkin elmer CHNS/O Analyzer 2400 Series II, Infrared spectra were recorded in KBr pellets on a Perkin-elmer Spectrum GX FT-IR model, NMR were recorded on Hitachi R-1500, TLC (Thin layer chromatograthy) was run on a glass plate using methanol-water-acetic acid (12:3:7) solvent system. A spot color was visualized by U.V. chamber. The equipment used for dying purpose was done by using HTHP dyeing machine (model - LL).

\subsection{Synthesis of bisazo disperse dyes}

\subsubsection{Diazotization}

Diazotization of various aromatic diamines 1(a-e) was carried out by the method reported in literature [13-18].

\subsubsection{Coupling procedure}

The coupling of above mentioned diazotized aromatic diamines was carried out in the similar manner. The general procedure adopted is given below:

2, 4-dihydroxybenzophenone $5.3 \mathrm{gm}(0.02 \mathrm{M})$ was dissolved in $30 \mathrm{ml}$ sodium hydroxide $(0.02 \mathrm{M})$ solution. The clear solution was cooled in ice-bath and diazonium solution of amine was added drop wise over 30 minutes with vigorous stirring. The $\mathrm{pH}$ was maintained between 7.0 to 8 by simultaneous addition of $10 \%$ w/v sodium carbonate solution. Stirring was continued for 2 hours, allowing the temperature to rise to ambient. The dye was then filtered off, washed with warm water and with cold water until it becomes acid free, and was dried at $50^{\circ} \mathrm{c}$ in an oven. The dyes were designated as bisazo disperse dyes $\left(\mathrm{D}_{21-25}\right)$ re-precipitated from DMF. 
<smiles>[3H]C(C)(N)CC</smiles>

Diamines 1 (a-e) $\mathrm{a}=1,2$-phenylenediamine $\mathrm{b}=1,3$-phenylenediamine $\mathrm{c}=1,4$-phenylenediamine $\mathrm{d}=2$-Nitro-1,4-phenylenediamine $\mathrm{e}=4$-Nitro-1,2-phenylenediamine

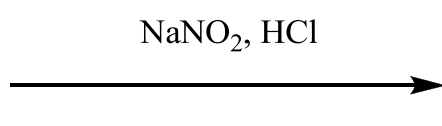

$0-5^{\circ} \mathrm{C}$<smiles>CC(C)(C)[N+]#[Ni]</smiles>

Bis-Diazonium salts 2 (a-e)<smiles>O=C(c1ccccc1)c1ccc(O)cc1O</smiles>

$+\mathrm{NaOH}, 0-5^{0} \mathrm{C}$

2,4-Dihydroxybenzophenone(DHBP)

(2 Moles)

$$
\operatorname{Ar} \longrightarrow \mathrm{N}=\mathrm{N} \longrightarrow(\mathrm{DHBP})]_{2}
$$

Bisazo DisperseDyes $\left(\mathrm{D}_{21}-\mathrm{D}_{25}\right)$

Scheme1. Synthesis of bisazo disperse dyes (D21-25) based on UV absorbing Material.

\subsection{Dyeing method for bisazo disperse dyes}

Dyeing of polyester fiber [19] is convenient at $90-135{ }^{\circ} \mathrm{c}$ and at high pressure (24-30 psi) in the laboratory. A model glycerin-bath high-temperature beaker and HTHP-LL dyeing machine was used. For this purpose a paste of finely powdered dye $(50 \mathrm{mg})$ was prepared with dispersing agent Dodamol $(90 \mathrm{gm})$ wetting agent Tween-80 (5 mg) and water $(5 \mathrm{mg})$ in a ball mill. To this paste, water $(99 \mathrm{ml})$ was added with stirring and the $\mathrm{pH}$ was adjusted to $4.5-5$ using acetic acid, the previously mentioned dye suspension $(100 \mathrm{ml})$ was added to a beaker provided with a lid and a screw cap. Before closing the lid and lightening the metal cap over the beaker a wetted pattern of polyester was rolled in to the beaker, and then placed vertically on the rotatory carrier inside the tank and the clamp plate was firmly tightened. The rotatory carrier was then allowed to rotate in the glycerin-bath and the temperature was raised to $90{ }^{\circ} \mathrm{C}$ at the rate of $2^{0} \mathrm{C} / \mathrm{min}$. The dyeing was continued for 1 hour under pressure. After cooling for 1 hour, the beaker was removed from the bath and washed with distilled water. The dyed pattern was thoroughly washed with hot water at $50{ }^{\circ} \mathrm{C}$ and then with cold water and dried at room temperature.

\subsection{Determination of the percentage exhaustion and fixation}

The dye bath percentage exhaustion and fixation of the dyed fabric was determined according to the known method [20] shown in Table 2.

Table1. List of Bisazo disperse dye structure $\left(\mathrm{D}_{21-25}\right)$

\begin{tabular}{|l|l|l|}
\hline $\begin{array}{l}\text { Dyes } \\
\text { No. }\end{array}$ & Aromati diamines 1(a-e) & Bisazo disperse dye structure $\left(\mathrm{D}_{21-25}\right)$ \\
\hline
\end{tabular}




(1,2-phenylenediamine

Table2. Absorption maxima, Exhaustion (E) and Fixation (F) of Bisazo Disperse dyes on polyester.

\begin{tabular}{ccccc}
\hline $\begin{array}{c}\text { Dyes } \\
\text { No. }\end{array}$ & $\begin{array}{c}\text { Absorption maxima } \\
\lambda \text { max/nm } \\
\text { in } \\
\text { DMF }\end{array}$ & \multicolumn{3}{c}{$\begin{array}{c}\text { Disperse dyeing on } \\
\text { Polyester }\end{array}$} \\
\cline { 3 - 5 } & 445 & Log $\boldsymbol{\varepsilon}$ & $\mathbf{\%}$ & $\% \mathbf{F}$ \\
\hline $\mathrm{D}_{21}$ & 430 & 4.5 & 76 & 93 \\
$\mathrm{D}_{22}$ & 455 & 4.2 & 68 & 75 \\
$\mathrm{D}_{23}$ & 448 & 4.6 & 80 & 92 \\
$\mathrm{D}_{24}$ & 420 & 4.5 & 78 & 83 \\
$\mathrm{D}_{25}$ & & 4.2 & 72 & 83 \\
\hline
\end{tabular}

\subsection{Fastness property}

The fastness to light, sublimation and perspiration of dye pattern was assessed according to British standard: 1006-1978 and the wash fastness test according to Indian standard: IS: 765-1979. The rubbing fastness was tested by using Crock meter (Atlas) AATCC-1961, shown in Table 3. 
Synthesis, Structure Investigation and Dyeing Assessment of Novel Bisazo Disperse Dyes Derived

Table3. Result of dyeing and various fastness properties of Bisazo Disperse dyes onto polyester.

\begin{tabular}{|c|c|c|c|c|c|c|c|c|}
\hline \multirow[t]{2}{*}{$\begin{array}{l}\text { Dyes } \\
\text { No. }\end{array}$} & \multirow[t]{2}{*}{$\begin{array}{l}\text { Color shades on } \\
\text { wool }\end{array}$} & \multirow[t]{2}{*}{$\begin{array}{l}\text { Light } \\
\text { fastness }\end{array}$} & \multirow[t]{2}{*}{$\begin{array}{l}\text { Wash } \\
\text { fastness }\end{array}$} & \multicolumn{2}{|c|}{ Perspiration fastness } & \multirow[t]{2}{*}{$\begin{array}{l}\text { Sublimation } \\
\text { fastness }\end{array}$} & \multicolumn{2}{|c|}{$\begin{array}{l}\text { Rubbing } \\
\text { fastness }\end{array}$} \\
\hline & & & & Acid & Alkaline & & Dry & Wet \\
\hline $\mathrm{D}_{21}$ & Reddish Brown & 5 & 5 & 4 & 4 & 4 & 4 & 4 \\
\hline$D_{22}$ & DarkYellow & 5 & 4 & 4 & 5 & 4 & 4 & 4 \\
\hline $\mathrm{D}_{23}$ & Brown & 5 & 4 & 4 & 4 & 5 & 4 & 4 \\
\hline $\mathrm{D}_{24}$ & Dark-Brown & 5 & 5 & 4 & 4 & 4 & 4 & 4 \\
\hline $\mathrm{D}_{25}$ & Light orange & 5 & 4 & 4 & 4 & 4 & 4 & 4 \\
\hline
\end{tabular}

III. RESULT \& DISCUSSION

\subsection{Physical properties of dyes}

All the dyes are obtained as amorphous powder ranging from yellow orange to reddish brown in colour. The purity of the dyes were checked by TLC using methanol-water-acetic acid (12:3:7) solvent system. The TLC results show that only single spot observed for each dye. The purified dyes have melting points measured by open capillary tube. The melting points were uncorrected.

The results of elemental analysis content of each dye are consistent with the predicted structure as shown in Scheme 1.

The number of azo group is almost one for each dye. The nitrogen content and number of azo group for each dye are co-related with each other. The IR spectrum of each dye comprises the important features (shown above) of aromatic, azo, hydroxyl and keto groups. The NMR spectra also give important signal at their respective positions. All diazo compounds based on the well known structure of 2, 4-dihydroxybenzophenone and reactive site for azo coupling, the structure of bisazo disperse dyes shown in Scheme 1 and in Table 1 is confirmed.

The visible absorption spectroscopic properties of dye were recorded in DMF solution. The absorption maxima ( $\lambda \max )$ of all dyes fall into the range of $420-455 \mathrm{~nm}$ in DMF, as shown in Table 2 . The value of the logarithm of molar extinction coefficient ( $\log \varepsilon$ ) of all the dyes were in the range of 4.2-4.6 consistent with their high intensity of absorption.

More ever the presence of electron donating or electron attracting groups did not bring about any marked increase or decreased in $\lambda_{\max }$ in the visible region and that $\log \varepsilon$ remained nearly constant. However electron attracting substituents like $-\mathrm{NO}_{2}$ in the substituent group of the coupler increase polarizability, and will result in bathochromic shifts. This leads to decrease in energy between the highest occupied molecular orbital and lowest unoccupied molecular orbital and thus $\pi \rightarrow \pi^{*}$ electron transition takes place at lower frequency photon resulting in the bathochromic shift of the visible absorption band.

\subsection{Analytical and spectral data of the dyes}

3.2.1.(5,5'-(1E)-1,2-phenylenebis(diazene-2,1-diyl)bis(2,4-dihydroxy-5,1-phenylene))bis(phenylmethanone) $\left(\mathbf{D}_{21}\right)$.

Calculated for $\mathrm{C}_{32} \mathrm{H}_{22} \mathrm{~N}_{4} \mathrm{O}_{6}$ : m.wt.: $558.54, \%$ yield 68 , m.p.: $240-244^{0} \mathrm{C}$, Rf. value: 0.78; C, $68.81 \%$; H, 3.97\%; N, 10.03\%; O, $17.19 \%$ Found: C, 68.81\%; H, 3.97\%; N, 10.03\%; O, $17.19 \%$. IR : $3460 \mathrm{~cm}^{-1}(-\mathrm{OH})$; $3077 \mathrm{~cm}^{-1}(=\mathrm{CH}$. aromatic $) ; 1630 \mathrm{~cm}^{-1}(\mathrm{C}=\mathrm{O}$, diaryl $), 1525 \mathrm{~cm}^{-1}(\mathrm{~N}=\mathrm{N}) ; 1484 \mathrm{~cm}^{-1}(\mathrm{C}=\mathrm{C}$ aromatic $) ; 1338 \mathrm{~cm}^{-1}$ $(\mathrm{C}-\mathrm{N}), 1123 \mathrm{~cm}^{-1}$ (C-O); $737 \mathrm{~cm}^{-1}, 586 \mathrm{~cm}^{-1}, 480 \mathrm{~cm}^{-1} .{ }^{1} \mathrm{H}-\mathrm{NMR}: 8.20 \delta(\alpha, 2 \mathrm{C}-\mathrm{H}$, for phenylenbisazo), $7.85 \delta(\beta$, $2 \mathrm{C}-\mathrm{H}$, for phenylenbisazo), 6.8-7.5 $\delta$ (Ar-H, multiplet), $5.35 \delta$ (Ar-OH, singlet).

3.2.2.(5,5'-(1E)-1,3-phenylenebis(diazene-2,1-diyl)bis(2,4-dihydroxy-5,1-phenylene))bis(phenylmethanone) $\left(\mathbf{D}_{22}\right)$

Calculated for $\mathrm{C}_{32} \mathrm{H}_{22} \mathrm{~N}_{4} \mathrm{O}_{6}$ : m.wt.: 558.54, \% yield: 77, m.p.: 222-226 ${ }^{0} \mathrm{C}$, Rf. value: 0.68; C, 68.81\%; H, 3.97\%; N, 10.03\%; O, 17.19\%\%. Found : C, 68.68\%; H, 3.91\%; N, 9.03\%; O, 17.10\%. IR : $3453 \mathrm{~cm}^{-1}(-$ $\mathrm{OH}) ; 3087 \mathrm{~cm}^{-1}\left(=\mathrm{CH}\right.$ aromatic); $1628 \mathrm{~cm}^{-1}\left(\mathrm{C}=\mathrm{O}\right.$, diaryl), $1528 \mathrm{~cm}^{-1}(\mathrm{~N}=\mathrm{N}) ; 1490 \mathrm{~cm}^{-1}(\mathrm{C}=\mathrm{C}$. aromatic $) ; 1348$ $\mathrm{cm}^{-1}$ (C-N), $1100 \mathrm{~cm}^{-1}$ (C-O); $740 \mathrm{~cm}^{-1}, 568 \mathrm{~cm}^{-1}, 479 \mathrm{~cm}^{-1} .{ }^{1} \mathrm{H}-\mathrm{NMR}: 8.20$ to $8.40 \delta(\alpha, 3 \mathrm{C}-\mathrm{H}$, for phenylenbisazo), $7.85 \delta(\beta, 1 \mathrm{C}-\mathrm{H}$, for phenylenbisazo), 6.8-7.5 $\delta$ (Ar- $\mathrm{H}$, multiplet), $5.35 \delta$ (Ar-OH, singlet).

3.2.3. (5,5'-(1,4-phenylenebis(diazene-2,1-diyl))bis(2,4-dihydroxy-5,1-phenylene))bis(phenylmethanone) $\left(\mathbf{D}_{23}\right)$.

Calculated for $\mathrm{C}_{32} \mathrm{H}_{22} \mathrm{~N}_{4} \mathrm{O}_{6}$ : m.wt.: $558.54, \%$ yield: 75 , m.p. : $209-211^{\circ} \mathrm{C}$, Rf. value: $0.72 ; \mathrm{C}, 68.81 \%$; H, 3.97\%; N, 10.03\%; O, $17.19 \%$ Found: C, $68.76 \% ; \mathrm{H}, 3.95 \%$;, $10.00 \%$; O, 16.19\%. IR : $3480 \mathrm{~cm}^{-1}(-\mathrm{OH})$; $3072 \mathrm{~cm}^{-1}(=\mathrm{CH}$ aromatic $), 1631 \mathrm{~cm}^{-1}(\mathrm{C}=\mathrm{O}$, diaryl $), 1540 \mathrm{~cm}^{-1}(\mathrm{~N}=\mathrm{N}), 1480 \mathrm{~cm}^{-1}(\mathrm{C}=\mathrm{C}$ aromatic $), 1339 \mathrm{~cm}^{-1}(\mathrm{C}-$ N), $1104 \mathrm{~cm}^{-1}(\mathrm{C}-0), 738 \mathrm{~cm}^{-1}, 560 \mathrm{~cm}^{-1}, 470 \mathrm{~cm}^{-1}$.

3.2.4.(5,5'-(2-nitro-1,4-phenylene)bis(diazene-2,1-diyl)bis(2,4-dihydroxy-5,1-phenylene))bis(phenylmethanone) $\left(\mathbf{D}_{24}\right)$. 
Calculated for $\mathrm{C}_{32} \mathrm{H}_{21} \mathrm{~N}_{5} \mathrm{O}_{8}$ : m.wt. : 603.54 , \% yield: 78, m.p. : $267-270^{\circ} \mathrm{C}$, Rf. value : 0.86; C, $63.68 \%$; $\mathrm{H}$, $3.51 \%$; N, $11.60 \%$; O, 21.21\%. Found: C, $63.61 \%$; H, 3.48\%; N, $11.55 \%$; O, 21.00\%. IR : $3636 \mathrm{~cm}^{-1} \quad(-\mathrm{OH})$, $3080 \mathrm{~cm}^{-1}$ (=CH aromatic); $1658 \mathrm{~cm}^{-1}\left(\mathrm{C}=\mathrm{O}\right.$, diaryl), $1531 \mathrm{~cm}^{-1}(\mathrm{~N}=\mathrm{N}) ; 1478 \mathrm{~cm}^{-1} \quad(\mathrm{C}=\mathrm{C}$ aromatic $) ; 1343 \mathrm{~cm}^{-}$ ${ }^{1}(\mathrm{C}-\mathrm{N}), 1103 \mathrm{~cm}^{-1}$ (C-O); $780 \mathrm{~cm}^{-1}, 741 \mathrm{~cm}^{-1}, 584 \mathrm{~cm}^{-1}, 489 \mathrm{~cm}^{-1}{ }^{1} \mathrm{H}-\mathrm{NMR}: 8.18$ to $8.86 \delta$ (3C-H, for Substituted phenylenbisazo)7.3-7.78 $\delta$ (Ar-H, multiplet), $5.35 \delta$ (Ar-OH, singlet).

3.2.5.(5,5'-(1E)-(4-nitro-1,2-phenylene)bis(diazene-2,1-diyl)bis(2,4-dihydroxy-5,1-phenylene))bis(phenyl methanone) $\left(\mathbf{D}_{25}\right)$.

Calculated for $\mathrm{C}_{32} \mathrm{H}_{21} \mathrm{~N}_{5} \mathrm{O}_{8}$ : m.wt.: $603.54, \%$ yield: 69 , m.p.: $198-204^{0} \mathrm{C}$, Rf. value: 0.77 ; C, $63.68 \%$; $\mathrm{H}, 3.51 \%$; N, $11.60 \%$; O, $21.21 \%$. Found: C, $63.68 \% ; \mathrm{H}, 3.51 \%$; N, $11.60 \%$; O, 21.21\%. IR : $3636 \mathrm{~cm}^{-1}$ $\mathrm{OH}), 3080 \mathrm{~cm}^{-1}(=\mathrm{CH}$ aromatic $) ; 1658 \mathrm{~cm}^{-1}\left(\mathrm{C}=\mathrm{O}\right.$, diaryl), $1531 \mathrm{~cm}^{-1}(\mathrm{~N}=\mathrm{N}) ; 1478 \mathrm{~cm}^{-1} \quad(\mathrm{C}=\mathrm{C}$ aromatic $) ; 1343$ $\mathrm{cm}^{-1}(\mathrm{C}-\mathrm{N}), 1103 \mathrm{~cm}^{-1}$ (C-O); $780 \mathrm{~cm}^{-1}, 741 \mathrm{~cm}^{-1}, 584 \mathrm{~cm}^{-1}, 489 \mathrm{~cm}^{-1}{ }^{1} \mathrm{H}-\mathrm{NMR}: 8.46$ to $8.86 \delta$ (3C-H, for Substituted phenylenbisazo) 7.3-7.78 $\delta$ (Ar-H, multiplet), $5.35 \delta$ (Ar-OH, singlet).

\subsection{Dyeing properties of dyes}

The bisazo disperse dyes were applied at $2 \%$ depth on polyester fabric respectively. Their dyeing properties are given in Table 3 . These bisazo disperse dyes gave a wide range of colour varying from yellow orange to reddish brown shades with good levelness, brightness and depth on the fabric. The dyeing showed an excellent fastness to light, with very good to excellent fastness to washing, perspiration and sublimation and it shows poor rubbing fastness(as shown in Table 3).

A remarkable degree of levelness after washing is observed very poor. This may be attributed to less penetration and affinity of the bisazo disperses dyes in to fiber structure.

\section{CONCLUSIONS}

Produced bisazo disperse dyes have good fastness to light, sublimation and perspiration but show poor rubbing fastness properties. The nature of the substituent in the coupling components has a little influence on the visible absorption and shade of the dyeing.

\section{Acknowledgements}

The author is thankful to the Principal, V. P. \& R. P. T. P. Science College and C. V. M. for providing the necessary research facilities. The author is also thankful to the Color Tax (Pvt) Ltd.,Surat, India, for characterization of the azo groups and giving the standard of fastness properties and to Raju Mehta of G.P.C.B., Surat, India, for providing useful chemicals.

\section{REFERENCES}

[1] C. T. Kosolia and E. G. Tsatsaroni, Journal of Applied Polymer Science, 116 (3), 2010, 1422.

[2] J. Kling, S. H. Silva and B. AraujoNeto, Journal of Biotechnology, 21(3), 1991,295.

[3] H. Lee, J. C. Mason and S. Achilefu, J. Org. Chem., 71(20), 2006,7862.

[4] T. Yamaguchi and M. Irie, J. Org. Chem., 70(25), 2005, 10323.

[5] T. Yamaguchi, S. Takamiband and M. Irie, Journal of Photochemistry and Photobiology A: Chemistry, 193(2-3) 2008,146.

[6] P. Mehta, M. Surana, R. Mehta and B.V. Kabra, Der Chemica Sinica, 2(5), 2011, 37.

[7] B. S. Dawane, S. S. Chobe, G. G. Mandawad, B. M. Shaikh, S. G. Konda and S. D. Patil, Der Pharmacia Sinica, 1(3), $2010,140$.

[8] T. Bentin, R. Hamzavi, J. Salomonsson, H. Roy, M. Ibba and P.E. Nielsen, The Journal of Biological Chemistry, 279, $2004,19839$.

[9] M. Tamura, T. Ohishi and H. Sakurai, US Patent. 4, 298, $522,1981$.

[10] F. I Farouqui and I. Hossain, (Dep. appl. chem. chem. Technol., Rajshahi Univ. Rajshahi, Bangladesh). Text Dyer Printer 23(1), 1990,15-18

[11] R.W. Layer, US Patent. 4, 133,799, (1979).

[12] N. Seto, and M. Morigaki, US Patent. 4, 864,039 (1989).

[13] F. David and H.E. Blengy, Fandamental process of Dye chemistry (New York: Willy, 241 1949).

[14] H. M. Patel, Der Chemica Sinica. 2(6) (2011) 89

[15] H. M. Patel, Der Chemica Sinica. 3(1) (2012) 175

[16] H. M. Patel, Advances in Applied Science Research. 3(1) (2012) 235

[17] H. M. Patel, Orbital the electronic journal of chemistry. 4(3) (2012) 159.

[18] H. M. Patel, J. Serb. Chem. Soc.. 77(11) (2012) 1551.

[19] G. M. Malik and S. K. Zadafiya, Der Chemica Sinica, 1 (3), 2010, 15.

[20] R. M. E. Shishtawy, Y. A. Youssef, N. S. E. Ahmed and A. A. Mousa, Dyes and Pigments 72,2007, 57. 